\title{
E-MRS Holds 1988 Spring Meeting in Strasbourg
}

The 1988 Spring Meeting of the European Materials Research Society is being held May 31-June 2 at the Council of Europe building in Strasbourg, France. The meeting will bring together researchers and industrial managers to focus on creating a synergy between innovative technolgies, exchanging information, and promoting technology transfer.

This year's program will feature four invited plenary lectures and four topical symposia, highlighted below. The opening session will be hosted by J.P. Massue, Scientific Advisor to the Parliamentary Assembly, Council of Europe, and by J.G. Wurm of the Commission of European Communities.

The plenary session will feature four invited lectures:

"Future VLSI Technology" by M. Hirose (Hiroshima University, Japan);

"Analytical Field Ion Microscopy of Hard Magnets" by P. Haasen (University of Gottingen, W. Germany);

"Delta Doping Interfaces" (tentative title) by F. Koch (Technical University of Munich, W. Germany); and

"Superconducting Ceramics: The Materials Challenge" by C.J. Humphreys (University of Liverpool, United Kingdom).

Awards for young scientists will be presented at the end of the opening session in recognition of the best papers presented during the E-MRS meeting. Each symposium will grant two awards for original, significant, and interesting papers presented by young scientists. Each award will comprise a certificate, waiver of the meeting fee, cash award of $100 \mathrm{ECU}$, and a special badge.

\section{Symposium A-Ceramic Materials Research}

Chairman: R.J. Brook (University of Leeds, Department of Ceramics, United Kingdom).

Eight sections in this symposium will highlight areas of promise and particularly rapid advance. Invited speakers will review international developments and report on research advances within the European Community. The eight sections and their chairmen are: Fabrication-F. Cambier (CRIBC, Mons, Belgium); Characterization-P. Boch (ENSCI, Limoges, France); Engineering CeramicsD. Broussaud (Ecole Nationale Superieure des Mines de Paris, France); Innovation in Technical Ceramics-C. Palmonari (Centro Ceramico, Bologna, Italy); Ceramics for Electronics-Dr. Greuter (BBC Brown Boveri Ltd., Baden, Switzerland); Applications and Properties-R. Telle (Max Planck Institut für Me- tallforschung, W. Germany); Powders and Raw Materials-D. Seyal (ESD, Oxon, United Kingdom); and Superconductors-N. Nygren (Stockholm University, Sweden).

\section{Symposium B-Photon, Beam, and Plasma-Assisted Processing Fundamentals and Device Technology}

Chairmen: I.W. Boyd (Department of Electronic and Electrical Engineering, University College London, United Kingdom); E.F. Krimmel (Siemens A.G., Munich, W. Germany).

This symposium will highlight potential applications of emerging technologies using lasers, incoherent light, charged particle beams and plasmas to enhance or induce epitaxy, surface and interface chemistry, and phase transformation processes. Emphasis will be on interaction and process mechanisms, processinduced defects, preparation of materials, and impact on device processing. Invited speakers include: Bicknell (Würzburg, W. Germany); Briones (CNM, Madrid, Spain; Mihaelescu (Bucharest, Romania); Trundle (Plessey, U.K.); Flickstein (CNET, France); R. Lawes (Rutherford AL, U.K.); J. Nijs (IMEC, Belgium); Eisele (Munich, W. Germany); Fotakis (Crete, Greece); R. Jackson (IBM, San Jose, CA, U.S.A.) G. Loper (Aerospace Corp, LA, U.S.A.); F. Harriott (AT\&T Bell Labs, NJ, U.S.A.); R.B. Jackman (Oxford, U.K.); R. Burcke or C. Pomot (CNET, Meylan, France).

\section{Symposium C-Deep Implants:} Fundamentals and Applications

Chairmen: G.G. Bentini (CNR - Istituto LAMEL, Bologna, Italy); A. Golanski (CNET Grenoble, Meylan, France); S. Kalbitzer (MPI für Kernphysik, Heidelberg, W. Germany).

This symposium will highlight the experimental and theoretical aspects of the physical and technological problems involved in new applications of high energy $(\mathrm{MeV})$ ion beams. Topics include: range and damage distributions, doping profiles, chemical layer formation, new characterization techniques, new applications of high energy ion beams, high energy implanted VLSI device fabrication, high energy implantation induced defects and their impact on device performance, and machines for high energy ion implantation.

Invited speakers include: $H$. Baumgart (Philips Research Labs, Eindhoven, Netherlands); J.P. Biersack (Hahn-MeitnerInstitut für Kernforschung, Berlin, W. Germany); E.H. Te Kaat (University of Dortmund, Netherlands); A.M. Mazzone
(CNR-LAMEL, Bologna, Italy); J. Middelhoek (University of Twente, Netherlands); J. Poate (AT\&T Bell Labs, NJ, U.S.A.); O. Puglisi (University of Catania, Italy); S. Saris (FOM Institut, Amsterdam, Netherlands); and A.N. Saxena (Rensselaer Polytechnic Institute, NY, U.S.A.).

\section{Symposium D-Preparation and Properties of Mestable Alloys}

Chairmen: K. Samwer (G. August Universitaet, Gottingen, W. Germany); $M$. von Allmen (CM S.A., Bienne, Switzerland); J. Bottiger (Institute of Physics, Aarhus, Denmark); B. Stritzker, IFF-KFA, Jülich, W. Germany).

This symposium will bring together scientists involved in both basic and applied research to focus on the fundamental relationships of the formation of metastable alloys, such as amorphous alloys and microcrystalline alloys, and their applications. Invited speakers include: W.L. Johnson (Caltech, Pasadena, CA, U.S.A.); A.R. Miedema (Philips Research Labs, Eindhoven, Netherlands); A.L. Greer (University of Cambridge, U.K.); L. Schultz (Siemens Research Lab, Erlangen, W. Germany); A. Traverse $/ \mathrm{H}$. Bernas (CSNSM, Orsay, France); J.M. Dubois (CNRS-Ecole des Mines, Nancy, France); J. Hafner (T. Universitaet, Vienna, Austria); K. Urban (IFF-KFA, Jülich, FRG); and K.H.J. Buchhow (Philips Research Labs, Eindhoven, Netherlands).

\section{For information about E-MRS, contact:}

$$
\text { P. Siffert }
$$

Centre de Recherches Nucléaires Laboratoire PHASE 67037 Strasbourg Cedex France

Telephone: (88) 286543 Fax: (88) 280990 Telex: CNRS CRO 890032F 